\title{
BLEFAROPLASTI TEKNIK CUTLER-BEARD PADA KARSINOMA KELENJAR SEBASEA
}

\author{
${ }^{1}$ Linda Vonica \\ ${ }^{2}$ Grando Setiawan \\ ${ }^{2}$ Josefien S. M. Saerang
}

\begin{abstract}
Bagian Ilmu Penyakit Mata Fakultas Kedokteran Universitas Sam Ratulangi Manado Email: linda.vonica@yahoo.com
\end{abstract}

\begin{abstract}
Sebaceous gland carcinoma is derived from Meibomian gland, Zeis gland, or sebaceous gland of caruncula. It is frequently misdiagnosed or late diagnosed because the lesion looks like chalazion or chronic blepharoconjunctivitis. The recommended therapy is wide local excision of the nodular lesion. Reconstruction of the eyelid will be done after the tumor resection either congenital or traumatic deffects. Defect of the upper eyelid that covers more than $50 \%$ of the margin needs wider excision. We reported a 48 -year-old female with a lump on the right upper eyelid since a year ago associated with wedging sensation, sometimes itchy. The tumor grew slowly and had undergone curettage for 3 times. Opthalmological examination showed an irregular-formed tumor on the right upper eyelid, 1x1,5 cm, irregular surface, discrete border, associated with hard, painless, and immobile in palpation. Excision of the tumor was followed by a blepharoplasty with a Cutler-Beard flap. The pathological examination indicated a sebaceous gland carcinoma. Conclusion: In this case, the diagnosis of sebaceous gland carcinomas was confirmed based on anamnesis, opthalmological examination, and pathology examination. Excision of the tumor was followed by a blepharoplasty with a Cutler-Beard flap because the eyelid defect exceeded 50\% of its margin.

Keywords: sebaceous gland, blepharoplasty, Cutler-Beard
\end{abstract}

\begin{abstract}
Abstrak: Karsinoma kelenjar sebasea merupakan tumor ganas berpotensi mematikan yang berasal dari kelenjar Meibom, kelenjar Zeis, atau kelenjar sebasea dari karunkula. Diagnosis klinis sering terlewat atau tertunda karena lesi menyerupai kalazion atau blefarokonjungtivitis kronis. Rekomendasi terapi meliputi eksisi lokal luas pada lesi nodular. Rekonstruksi kelopak dilakukan pada defek setelah reseksi tumor baik kongenital maupun defek traumatik. Defek kelopak atas yang mengenai margin lebih dari 50\% memerlukan perluasan jaringan sekitar. Kami melaporkan seorang pasien perempuan berusia 48 tahun dengan keluhan utama benjolan pada kelopak atas mata kanan sejak 1 tahun lalu disertai rasa mengganjal dan kadang-kadang terasa gatal. Benjolan membesar secara perlahan dan tetap ada walaupun sudah dikuret sebanyak 3 kali. Pada pemeriksaan oftalmologi palpebra mata kanan terdapat benjolan bentuk tidak beraturan, permukaan tidak rata, ukuran $1 \times 1,5 \mathrm{~cm}$, berbatas tegas, konsistensi keras, tidak nyeri tekan dan tidak mobile bila digerakkan. Tumor dieksisi dan dilakukan blefaropasti teknik Cutler-Beard. Hasil pemeriksaan patologi jaringan tumor menunjukkan suatu karsinoma kelenjar sebasea. Simpulan: Pada kasus ini, diagnosis karsinoma kelenjar sebasea ditegakkan berdasarkan anamnesis, pemeriksaan oftalmologis, dan pemeriksaan patologi. Eksisi tumor pada karsinoma kelenjar sebasea diikuti dengan blefaroplasti teknik Cutler-Beard karena defek pada kelopak mata atas lebih dari 50\%.
\end{abstract}

Kata kunci: blefaroplasti, Cutler-Beard, karsinoma kelenjar sebasea 
Kulit kelopak mata terdiri dari epidermis yang merupakan epitel berlapis gepeng lapisan tanduk serta mengandung melanosit dan sel Langerhans; dan dermis yaitu jaringan penyambung kolagen longgar yang mengandung silia dan kelenjar sebasea Zeiss, kelenjar keringat apokrin Moll, kelenjar keringat ekrin, dan unit pilosebasea. $^{1}$

Karsinoma kelenjar sebasea merupakan salah satu karsinoma pada palpebra yang meliputi 1-5,5\% dari keganasan kelopak dan merupakan keganasan kelopak tersering nomor 3 setelah karsinoma sel basal dan karsinoma sel skuamosa, meskipun beberapa laporan menempatkan tumor ini sebagai nomor 2 tersering setelah karsinoma sel basal. Karsinoma kelenjar sebasea merupakan tumor ganas dan berpotensi mematikan yang berasal dari kelenjar meibom di tarsus, kelenjar Zeis pada kulit kelopak mata, atau kelenjar sebasea dari karunkula., ${ }^{2,3}$ Tumor berwarna kekuningan karena material lipid dalam sel neoplasma. Diagnosis klinis sering terlewat atau tertunda karena lesi menyerupai kalazion atau blefarokonjungtivitis kronis. ${ }^{1-4}$

Rekomendasi terapi meliputi eksisi lokal luas pada lesi nodular. Kontrol batas operasi dengan bedah beku dan Mohs micrographic surgery membuat hasil suboptimal karena sulit mengidentifikasi perluasan intraepitelial. Angka keberhasilan karsinoma kelenjar sebasea lebih buruk daripada karsinoma sel skuamosa, tetapi membaik dalam beberapa tahun terakhir karena peningkatan kewaspadaan, deteksi dini, diagnosis lebih akurat, dan terapi tepat. Metastasis pertama meliputi kelenjar limfe regional. ${ }^{1}$

Rekonstruksi kelopak dilakukan pada defek setelah reseksi tumor baik kongenital maupun defek traumatik. Beberapa metode dapat dipilih untuk rekonstruksi defek kelopak tertentu. Defek kecil yang mencakup margin kelopak atas dapat diperbaiki dengan menutup langsung jika tidak menyebabkan terlalu banyak tekanan pada luka. Penutupan langsung biasanya dilakukan jika margin kelopak yang terkena $\leq 33 \%$. Defek sedang pada margin kelopak atas (33-50\%) dapat diperbaiki dengan penarikan segmen lateral kelopak. Defek kelopak atas yang mengenai margin $>50 \%$ memerlukan penarikan jaringan sekitar. ${ }^{3-5}$

\section{LAPORAN KASUS}

Seorang pasien perempuan berusia 48 tahun datang ke poli mata RSUP Prof. Dr. R. D. Kandou Manado dengan keluhan utama terdapat benjolan pada kelopak atas mata kanan sejak 1 tahun lalu. Benjolan mula-mula kecil kemudian membesar secara perlahan. Pernah dilakukan kuretase sebanyak 3 kali namun benjolan tetap ada. Juga disertai rasa mengganjal dan kadangkadang terasa gatal.

Pada pemeriksaan fisik didapatkan keadaan umum baik, kesadaran kompos mentis, tanda-tanda vital dalam batas normal, serta pemeriksaan kepala, leher, dan kelenjar getah bening tidak ada kelainan. Pemeriksaan jantung, paru, abdomen, dan ekstremitas dalam batas normal.

Pada pemeriksaan oftalmologi didapatkan VOD: 6/6 addisi S+2,00, VOS: 6/15 dikoreksi dengan S-1,50 6/6 addisi S+2,00. Tekanan intra okuler ODS: normal/palpasi. Regio orbita dan adneksa ODS dalam batas normal. Segmen anterior OD ditemukan pada palpebra terdapat benjolan berbentuk tidak beraturan, permukaan tidak rata, ukuran $1 \times 1,5 \mathrm{~cm}$, berbatas tegas, konsistensi keras, tidak nyeri tekan dan tidak mobile pada pergerakan. Konjungtiva, kornea, kamera okuli anterior (COA), iris, pupil, dan lensa dalam batas normal. Segmen posterior OD dalam batas normal. Segmen anterior OS pada konjungtiva terdapat jaringan fibrovaskuler berbentuk segitiga dengan puncak di limbus. Palpebra, COA, iris, pupil dan lensa dalam batas normal. Segmen posterior OS dalam batas normal.

Pasien didiagnosis dengan suspek karsinoma glandula sebasea OD, pterigium grade 1 OS, miopia OS, dan presbiopia. Pasien diberi terapi air mata buatan tetes mata 3x1 gtt OS, pro eksisi tumor, dan blefaroplasti teknik Cutler-Beard OD. Anjuran pemeriksaan laboratorium darah 
(darah lengkap, faktor pembekuan, fungsi hati, fungsi ginjal, gula darah, profil lipid, asam urat), foto toraks, dan EKG untuk persiapan operasi dengan anestesi umum, dan FNAB.

Hasil FNAB mikroskopik ialah hapusan tampak kelompok sel-sel epitel yang anaplastik bahkan beberapa sel yang bizzare dengan kromatin inti kasar, cyst macrophag, sel-sel radang limfosit, leukosit PMN, dan sel darah merah. Simpulan yaitu suatu proses malignansi epitelial yang belum dapat ditentukan asalnya disertai infeksi sekunder

Hasil EKG, foto toraks, dan laboratorium darah dalam batas normal.

Pasien dilakukan operasi eksisi tumor dan blefaroplasti teknik Cutler-Beard tahap 1 pada tanggal 20 November 2013. Pemeriksaan patologi jaringan tumor memperlihatkan hasil makroskopik jaringan $2 \times 2 \times 1 \mathrm{~cm}$, putih, kenyal, proses sebagian. Gambaran mikroskopik berupa jaringan dilapisi epitel pipih bertatah, subepitelial tampak berkelompok sel tumor terdiri dari sel-sel berbentuk bulat lonjong, kromatin inti granuler kasar, kadangkadang dengan nukleoli dan sitoplasma bervakuol. Kelompok sel tumor dibatasi jaringan ikat fibrosa, terlihat juga beberapa sel mitosis dengan simpulan tumor kelenjar sebasea.

Tanggal 17 Januari 2014 dilakukan operasi rekonstruksi teknik Cutler-Beard tahap 2.

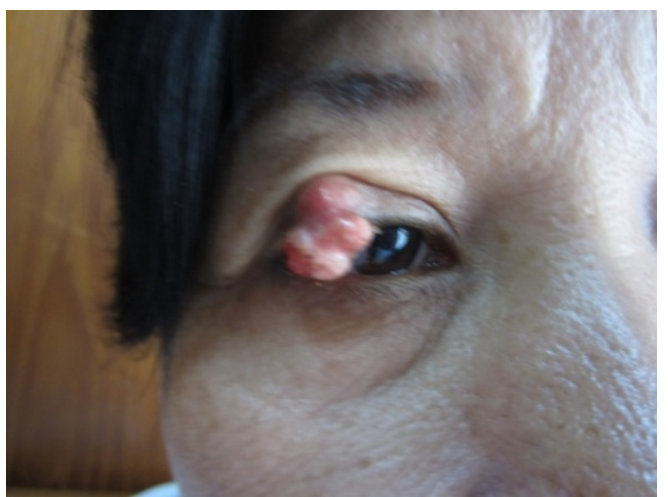

Gambar 1. Sebelum operasi eksisi tumor dan blefaroplasti teknik Cutler-Beard tahap 1

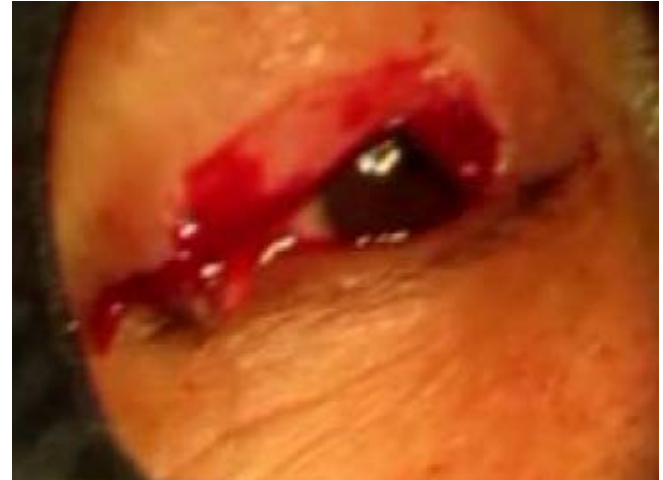

Gambar 2. Setelah eksisi tumor dan sebelum dilakukan blefaroplasti

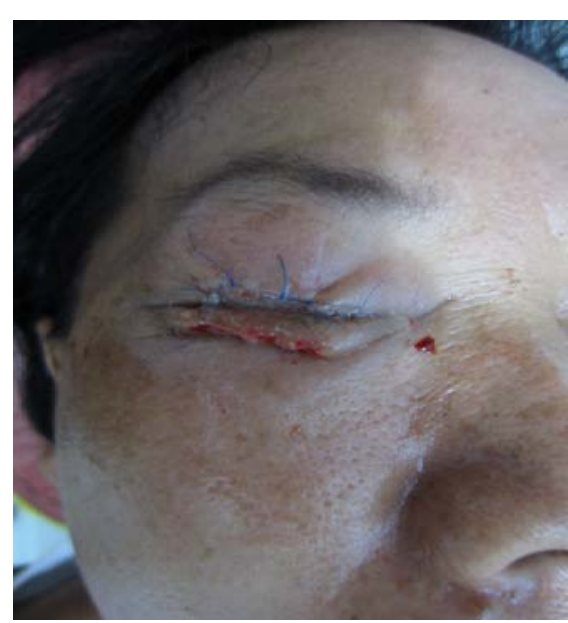

Gambar 3. Setelah operasi eksisi tumor dan blefaroplasti teknik Cutler-Beard tahap 1

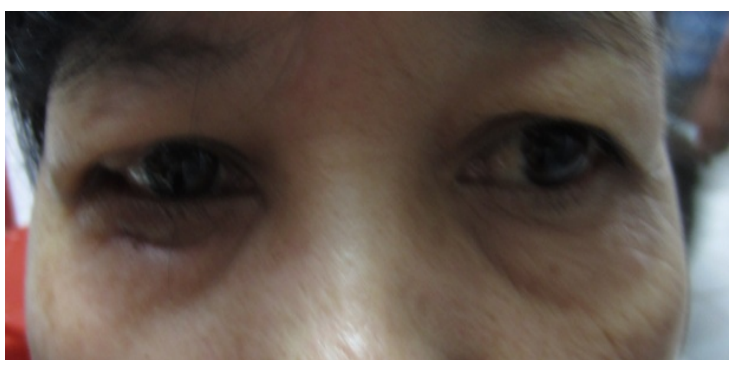

Gambar4. Setelah operasi blefaroplasti teknik Cutler-Beard tahap 2

\section{BAHASAN}

Diagnosis karsinoma kelenjar sebasea pada kasus ini ditegakkan berdasarkan anamnesis, pemeriksaan oftalmologis, serta pemeriksaan penunjang. Kondisi pasien ini sesuai dengan acuan pustaka yaitu karsinoma kelenjar sebasea lebih sering 
pada perempuan, dan $2 x$ lebih sering pada kelopak mata atas daripada yang bawah; hal ini sesuai dengan jumlah kelenjar meibom dan Zeis yang lebih banyak pada kelopak mata atas. Pasien biasanya berusia $>50$ tahun, tetapi tumor ini juga telah dilaporkan pada usia yang lebih muda. Tumor ini sering menyerupai kelainan jinak kelopak mata yaitu kalazion. ${ }^{1-4,7,8}$

Penyebab pasti karsinoma kelenjar sebasea masih belum diketahui. Untuk menegakkan diagnosis pasti diperlukan pemeriksaan patologi jaringan tersebut.

Pasien dilakukan operasi eksisi tumor secara full-thickness dengan margin 1-2 mm diluar tumor agar tumor dapat diangkat seluruhnya dan mencegah rekurensi. Setelah itu, jaringan dikirim ke Bagian Patologi Anatomi untuk pemeriksaan lebih lanjut dan didapatkan hasil tumor kelenjar sebasea.

Fungsi utama kelopak mata atas ialah melindungi mata dari benda asing dan menyediakan kontinuitas lapisan air mata pada kornea. Hal yang perlu diperhatikan dalam rekonstruksi defek kelopak mata atas ialah memperbaiki fungsi dan segi kosmetik kelopak mata dengan baik sehingga kelopak mata atas dapat bergerak dan menutup dengan baik agar tidak terjadi keratopati eksposur, serta adanya lipatan kelopak mata untuk alasan kosmetik. ${ }^{11,12}$ Rekonstruksi defek kelopak mata yang tidak tepat dapat menyebabkan masalah serius seperti konjungtivitis, keratitis, dan deformitas estetika. ${ }^{11}$

Pada pasien ini dilakukan blefaroplasti dengan teknik Cutler-Beard karena defek pada margin kelopak mata atas $>50 \%$. $^{4-6,9,10}$ Prosedur Cutler-Beard dilakukan dengan insisi di bawah tarsus kelopak bawah, flapfull-thickness kelopak bawah dipindahkan ke defek kelopak atas dengan melewatkan flap di bawah sisa margin kelopak bawah dan dibiarkan selama beberapa minggu agar terjadi peregangan. Pada umumnya, flap dipisahkan dalam 8 minggu, namun Shuan menyatakan flap dapat dipisahkan dalam 2 minggu. ${ }^{11-13}$ Pada pasien ini, flap dipisahkan dalam 8 minggu dan tidak ditemukan adanya entropion pada kelopak mata atas.

Keuntungan flap ini ialah dapat digunakan pada hampir semua defek. Komplikasi flap meliputi entropion kelopak mata atas, iregularitas margin kelopak, hilangnya bulu mata, retraksi karena sikatriks kelopak inferior, dan nekrosis bridge flap. Flap Cutler-Beard merupakan pilihan yang baik dari segi anatomis pada defek luas kelopak mata atas. ${ }^{11}$

Prognosis kasus ini ialah dubia karena eksisi lengkap dengan margin yang bersih membuat prognosis lebih baik dan belum ditemukan adanya metastasis pada kelenjar getah bening. Bila belum terjadi metastasis angka mortalitas $0-15 \%$, sedangkan adanya metastasis mempunyai prognosis yang lebih buruk dengan angka mortalitas 5 tahun sebesar $50-67 \%{ }^{2}$

\section{SIMPULAN}

Karsinoma kelenjar sebasea memerlukan deteksi dini, diagnosis, dan penanganan yang tepat karena lesi menyerupai kalazion dan blefaritis kronis. Eksisi tumor pada karsinoma kelenjar sebasea dapat diikuti dengan blefaroplasti teknik Cutler-Beard bila defek pada kelopak mata atas lebih dari $50 \%$.

\section{DAFTAR PUSTAKA}

1. Zorab RA, Straus H, Arturo C, Tanaka S, Ray JD, Veen B, et al. Eyelids. In: Veen B, editor. Basic and Clinical Science Course section 4: Ophthalmic Pathology and Intraocular Tumors. San Fransisco: The Foundation of the American Academy of Opthalmology, 2011; p. 221-4.

2. Yanoff M, Duker JS. Eyelid malignancies. Vaughn GJ, Dortzbach RK, Gayre GS, editors. Ophthalmology (3rd ed.). Missouri: Mosby, 2008; p. 1436-8.

3. Wali UK, Mujaini AA. Sebaceous gland carcinoma of the eyelid. Oman J Ophthalmol. 2010;3(3):117-21.

4. Zorab RA, Straus H, Arturo C, Tanaka S, Ray JD, Veen B, et al. Classification and management of eyelid disorders. In: Veen B, editor. Basic and Cinical Science Course section 7: Orbit, eyelids, 
and larimal system. San Fransisco: The Foundation of the American Academy of Opthalmology, 2011; p. 173-5, 181-7.

5. Tse DT. Eyelid reconstruction. Kronish JW, editor. Color Atlas of Oculoplastic Surgery (2nd ed.). Philadelphia: Lippincot Williams \& Wilkins, 2011; p. 224-9.

6. Leatherbarrow B, editor. Eyelid and periocular reconstruction. Oculoplastic Surgery (2nd ed.). London: Informa Healthcare, 2011; p. 233-78.

7. Kanski JJ, Bowling B. Eyelids. In: Gabbedy R, editor. Clinical Ophthalmology: A systemic approach (7th ed.). Philadelphia: Elsevier Saunders, 2011; p. 20-1.

8. Glassman ML, Bashour M, Benchimol M. Sebaceous gland carcinoma. [cited 2014 Jan 20]. Available from: http://emedicine.medscape.com/article/1
213781.

9. Bashour M. Upper eyelid reconstruction procedures treatment \& management. [cited 2014 Jan 20]. Available from: http://emedicine.medscape.com/article/1 282054.

10. Yoon MK, McCulley TJ. Secondary tarsoconjunctival graft: a modification to the Cutler-Beard procedure. Ophthal Plast Reconstr Surg. 2013;29(3):227-30.

11. Rahmi D, Mehmet B, Ceyda B, Sibel O. Clinical study management of the large upper eyelid defects with Cutler-Beard flap. Journal of Ophthalmology. 2014; 2014:1-4.

12. Irvine McNab. A technique for reconstruction of upper lid marginal defects. Br J Ophthalmol. 2003;87:279-81.

13. Hsuan J, Selva D. Early division of a modified Cutler-Beard flap with a free tarsal graft. Eye. 2004;18:714-7. 